\title{
Do multi-ingredient protein supplements augment resistance training-induced gains in skeletal muscle mass and strength? A systematic review and meta- analysis of 35 trials
}

\author{
Kerry R O'Bryan, ${ }^{\oplus 1}$ Thomas M Doering, ${ }^{1}$ Robert W Morton, ${ }^{2}$ Vernon G Coffey, \\ Stuart M Phillips, ${ }^{\oplus 2}$ Gregory R Cox ${ }^{1}$
}

- Additional material is published online only. To view please visit the journal online (http://dx.doi.org/10.1136/ bjsports-2018-099889).

${ }^{1}$ Faculty of Health Sciences and Medicine, Bond University, Gold Coast, Queensland, Australia ${ }^{2}$ Department of Kinesiology, McMaster University, Hamilton, Ontario, Canada

Correspondence to

Mr Kerry R O'Bryan, Faculty of Health Sciences and Medicine, Bond University, Robina QLD 4226, Australia;

kerry.obryan@alumni.bond. edu.au

Accepted 8 February 2019
Check for updates

(C) Author(s) (or their employer(s)) 2019. No commercial re-use. See rights and permissions. Published by BMJ.

\footnotetext{
To cite: O'Bryan $K R$,

Doering TM,

Morton RW, et al.

Br J Sports Med Epub ahead of print: [please include Day Month Year]. doi:10.1136/ bjsports-2018-099889
}

\section{ABSTRACT}

Objective To determine the effects of multi-ingredient protein (MIP) supplements on resistance exercise training (RT)-induced gains in muscle mass and strength compared with protein-only (PRO) or placebo supplementation.

Data sources Systematic search of MEDLINE, Embase, CINAHL and SPORTDiscus.

Eligibility criteria Randomised controlled trials with interventions including RT $\geq 6$ weeks in duration and a MIP supplement.

Design Random effects meta-analyses were conducted to determine the effect of supplementation on fatfree mass (FFM), fat mass, one-repetition maximum (1RM) upper body and 1RM lower body muscular strength. Subgroup analyses compared the efficacy of MIP supplementation relative to training status and chronological age.

Results The most common MIP supplements included protein with creatine $(n=17)$ or vitamin $D(n=10)$. Data from 35 trials with 1387 participants showed significant $(p<0.05)$ increases in FFM $(0.80 \mathrm{~kg}(95 \% \mathrm{Cl} 0.44$ to 1.15)), 1RM lower body (4.22 kg (95\% Cl 0.79 to 7.64)) and 1RM upper body (2.56 kg (95\% Cl 0.79 to 4.33$)$ ) where a supplement was compared with all non-MIP supplemented conditions (means $(95 \% \mathrm{Cl})$ ). Subgroup analyses indicated a greater effect of MIP supplements compared with all non-MIP supplements on FFM in untrained $(0.95 \mathrm{~kg}(95 \% \mathrm{Cl} 0.51$ to 1.39$), \mathrm{p}<0.0001)$ and older participants $(0.77 \mathrm{~kg}(95 \% \mathrm{Cl} 0.11$ to 1.43$)$, $\mathrm{p}=0.02)$; taking MIP supplements was also associated with gains in 1 RM upper body $(1.56 \mathrm{~kg}(95 \% \mathrm{Cl} 0.80$ to 2.33), $p=0.01$ ) in older adults.

Summary/conclusions When MIP supplements were combined with resistance exercise training, there were greater gains in FFM and strength in healthy adults than in counterparts who were supplemented with non-MIP. MIP supplements were not superior when directly compared with PRO supplements. The magnitude of effect of MIP supplements was greater (in absolute values) in untrained and elderly individuals undertaking RT than it was in trained individuals and in younger people.

Trial registration number CRD42017081970.

\section{INTRODUCTION}

Resistance exercise training (RT) is a potent stimulus to promote protein synthesis in skeletal muscle ${ }^{1}$ and prolonged periods of RT generate

\section{What is already known}

- There is no consensus on whether multiingredient protein (MIP) supplementation combined with prolonged resistance exercise training (RT) modifies body composition and augments muscle strength.

\section{What are the new findings}

- MIP supplementation augments changes in fat-free mass (FFM), upper body onerepetition maximum strength and lower body one-repetition maximum strength during prolonged ( $\geq 6$ weeks) RT.

- The benefit of consuming an MIP supplement on resistance training-induced gains in FFM is greater in untrained participants $(0.95 \mathrm{~kg}$ [95\% $\mathrm{Cl} 0.51$ to 1.39$], \mathrm{p}<0.0001)$ than in the trained and in older individuals ( $>45$ years; $66 \pm 8$ years) compared with those below that age cut-off.

- MIP supplementation during RT is more effective at improving upper body strength gains in elderly individuals $(1.56 \mathrm{~kg}$ [95\% $\mathrm{Cl} 0.80$ to 2.33], $\mathrm{p}<0.0001$ ) than non-MIP supplements.

- MIP supplementation is not superior to proteinonly supplementation for increasing FFM and strength during periods of RT but does result in a greater increase in fat mass.

substantial gains in muscle mass. ${ }^{2}$ Typically, when individuals undertake RT with a diet that provides readily available essential amino acids in the postexercise period and adequate total protein intake $\left(\sim 1.6 \mathrm{~g} / \mathrm{kg}\right.$ body mass) ${ }^{3}$, they have a positive protein balance that promotes net gains in skeletal muscle mass. Some previous reports indicated that protein-only (PRO) supplementation augments the adaptive response of skeletal muscle to RT in older individuals, ${ }^{24}$ but others report only small effects. ${ }^{56}$ However, a recent systematic review and meta-analyses ${ }^{3}$ provides a comprehensive synthesis of current data and shows PRO supplementation is effective for increasing fat-free mass (FFM) in young, trained participants, but there was little benefit in older or untrained individuals. 
Multi-ingredient protein (MIP) supplements contain a variety of ingredients in addition to protein that may promote resistance exercise gains in muscle mass and strength compared with RT alone. ${ }^{7}$ Creatine $(\mathrm{Cr}),{ }^{8}$ vitamin D (vit D) ${ }^{9}$ and polyunsaturated fatty acids (PUFAs) ${ }^{10}$ are common components of MIP supplements-they may augment the exercise-induced anabolic response in muscle. $\mathrm{Cr}$ is purported to increase muscle mass and strength by indirectly promoting greater force production and training volume, which stimulates muscle protein synthesis. ${ }^{11}$ Vit $\mathrm{D}$ activates the extracellular signal-regulated kinase pathway to stimulate muscle cell proliferation and growth to impact muscle function. ${ }^{12}$ How PUFA augments muscle mass is not fully understood, but increased rates of muscle protein synthesis (MPS) ${ }^{13}$ and small changes within the muscle transcriptome are reported in humans. ${ }^{14}$ If (regular) protein supplementation is an effective strategy primarily limited to young, trained individuals, ${ }^{9}$ MIP supplementation may be a way to increase muscle mass and strength in a larger population.

Naclerio and Larumbe-Zabala ${ }^{15}$ have undertaken the only previous review of the effect of MIP supplementation on muscle mass and strength with RT. Among trained participants, they noted superior gains in lean body mass, FFM and strength compared with those who had been taking an iso-energetic equivalent carbohydrate (CHO) or non-whey supplement.

Therefore, the primary aim of our meta-analysis was to conduct a systematic and evidence-based assessment of the effects of MIP supplementation on resistance training-induced gains in muscle mass and strength in healthy adults. A secondary aim was to determine whether MIP supplements provided additional resistance training gains compared with PRO supplements.

\section{METHODS}

\section{Search strategy}

A systematic search of the literature was conducted by one author (KRO) in four databases, Ovid MEDLINE, Embase, CINAHL and SPORTDiscus, current to October 2017 (see supplementary appendix A). The following predefined keywords and search term combinations were used: 'protein intake'; 'resistance training'; 'weight lifting'; 'isometric contraction'; 'muscle strength'. Boolean operators (AND, OR) were used to concatenate the search terms.

\section{Inclusion criteria}

RCTs involving RT and consumption of an MIP supplement were considered for this meta-analysis. Trials were required to be a minimum of 6 weeks in duration with participants performing RT at least twice per week. A 'MIP supplement' was defined as a protein supplement with any additional ingredients added (eg, carbohydrate (CHO), Cr, $\beta$-hydroxy $\beta$-methylbutyrate (HMB), leucine (Leu), calcium, vit D and/or PUFAs). At least one group had to be given the MIP supplement that was not administered in conjunction with other androgenic compounds (eg, testosterone). The control group had to be supplemented with either a placebo (PLA), PRO or were a non-supplemented resistance training only group (RT). Only human trials using healthy individuals who were not energy restricted were considered. Manuscripts had to be original research (not a review or conference abstract) and written in English.

\section{Data extraction}

Details of interest and data from each trial were collected in an evidence table (table 1), which included the trial design, details of the RT intervention, participant characteristics, MIP supplement, PLA/control information, body composition and performance outcomes, and any other relevant information (eg, sources of bias/conflict of interest). Two reviewers worked independently where one author (KRO) extracted the relevant data from the included trials and another (TMD) verified the extracted data. Any discrepancies between the two authors were resolved through consensus or opinion of a third author (GRC). For each included trial, the corresponding author was contacted if any missing data or information was needed (13 trials). Where authors could not be contacted (8 of 13), data were either extracted using WebPlotDigitizer (Web Plot Digitizer, V.4.1. Texas, USA: Ankit Rohatgi, 2017) ${ }^{16-24}$ calculated from baseline values and/or percentage change ${ }^{24-26}$ or excluded from the meta-analysis. ${ }^{27}$

A total of 57 different body composition and 48 performance outcomes were extracted from the final 35 trials. $^{716-49}$ Primary outcome measures were restricted and merged where possible to include three body composition outcomes and two performance measures based on those most commonly reported in the 35 trials to maximise the power of analysis. Body anthropometric and composition outcomes assessed include: total body mass (TBM; measured by any scale); FFM and bone-free mass (or lean mass if FFM was not available) measured by dual-energy X-ray absorptiometry (DXA), hydrodensitometry/underwater weighing (UWW) or whole body air plethysmography (BodPod); and fat mass (FM; measured by DXA, UWW and/ or BodPod). Performance measures assessed include: one-repetition maximum strength for lower body (1RM lower body) and upper body exercises (1RM upper body; measured by any respective $1 \mathrm{RM}$ strength test, provided a multijoint exercise was also tested).

\section{Data syntheses}

Where necessary, reported data were converted to metric units (eg, $\mathrm{kg}$ ). If a trial included an MIP-supplemented RT group, a non-supplemented RT group and a no intervention control group, only the MIP and the RT groups were retrieved. Where a trial had multiple time points, only the preintervention and postintervention outcomes were retrieved. If a trial design included baseline measures during an initial phase that excluded $\mathrm{RT}$, the subsequent time point immediately preceding RT were retrieved and considered the baseline. If reported, the change in standard deviation $(\triangle \mathrm{SD})$ was retrieved with the preintervention and postintervention SD. Where $\Delta S D$ was not reported, a correlation coefficient (corr) for each primary outcome was calculated and used to impute the SD of change in accordance with the Cochrane Handbook for Systematic Reviews of Interventions ${ }^{50}$ : corr $=\left(\mathrm{SD}_{\text {pre }}{ }^{2}+\mathrm{SD}_{\text {post }}{ }^{2}-\mathrm{SD}_{\text {change }}{ }^{2}\right) /\left(2 \times \mathrm{SD}_{\text {pre }} \times \mathrm{SD}_{\text {post }}\right)$, and the $\triangle \mathrm{SD}$ was then calculated as:

$\Delta \mathrm{SD}=\sqrt{ }\left(\mathrm{SD}_{\text {pre }}^{2}+\mathrm{SD}_{\text {post }}^{2}-2 \times \operatorname{corr} \times \mathrm{SD}_{\text {pre }} \times \mathrm{SD}_{\text {post }}\right)$

Mean change ( $\Delta$ Mean) and $\Delta S D$ were calculated for each outcome and entered to RevMan (Review Manager [RevMan], V.5.3. Copenhagen: The Nordic Cochrane Centre, The Cochrane Collaboration, 2014). Three independent data comparisons were uploaded to RevMan for analyses: (1) MIP versus all non-MIP; (2) MIP versus PLA (CHO); and (3) MIP versus PRO. If a trial had more than one MIP group (eg, MIP pre-exercise and MIP postexercise), PLA/control group (PRO, PLA and RT) or measure of upper/lower body 1RM (eg, bench press and lateral pulldown), the $\Delta$ Mean and $\Delta S D$ were individually calculated and pooled with the RevMan calculator function for meta-analysis (RevMan, 2014). 


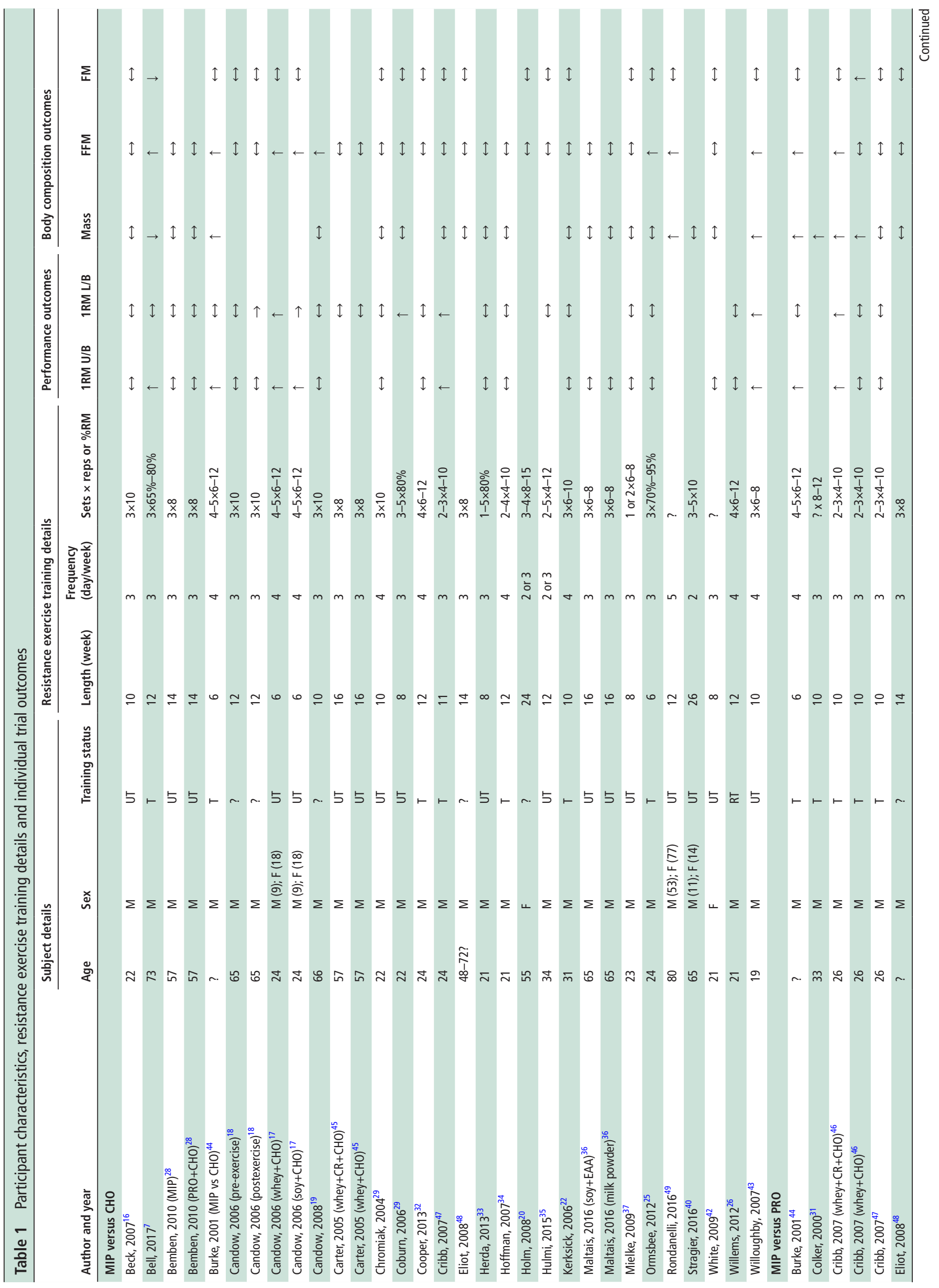




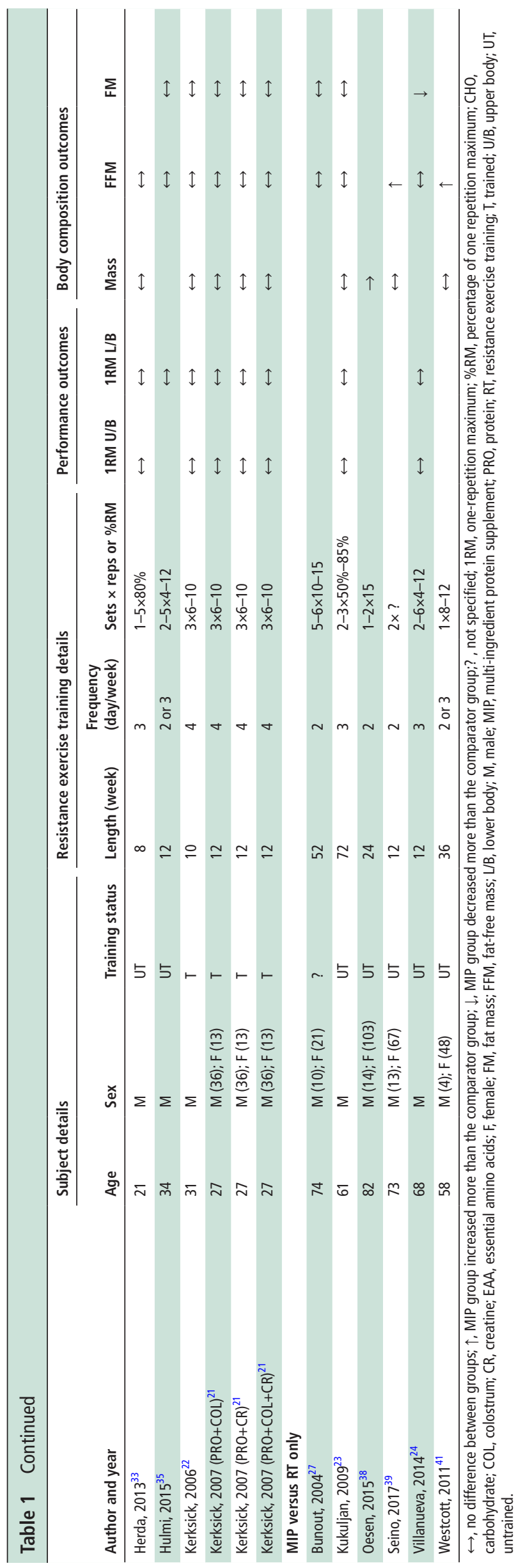

Data collection and analysis

The Cochrane collaboration tool ${ }^{50}$ for assessing risk of bias was applied to each trial independently by two investigators (KRO and TMD). A domain-based evaluation was conducted, with each trial scored low, unclear or high in seven domains: sequence generation, allocation concealment, blinding of participants and personnel, blinding of outcome assessment, incomplete outcome data, selective outcome reporting and other bias. Data were excluded from the meta-analyses if trials reported three or more high risk or unclear risk domains (see online supplementary figure 1).

To assess the methodological quality of the included trials, we used the GRADE system. ${ }^{51}$ We downgraded a starting rating of 'high quality' RCT evidence by one level for serious concerns (or by two levels for very serious concerns) about risk of bias, inconsistency, indirectness, imprecision or publication bias. Two authors (KRO and TMD) graded the evidence from high to very low for TBM, FFM, FM, 1RM lower body and 1RM upper body outcome measures.

\section{Meta-analyses}

Random effects meta-analyses were conducted in RevMan using the $\Delta$ Mean, $\Delta S D$ and sample size for each outcome. Effects are therefore presented as a mean difference (MD), with means \pm SD and 95\% CIs for TBM, FFM, FM, 1RM lower body and 1RM upper body. A further analysis of the included trials was conducted in RevMan that compared MIP and PRO conditions from the included trials and presented as forest plots. Due to six of the included trial designs involving an MIP, PRO and PLA groups, a subgroup analysis was not able to be performed.

Heterogeneity was evaluated in accordance with the Cochrane Handbook for Systematic Reviews of Interventions ${ }^{50}$ through interpreting $\mathrm{I}^{2}$ with significance set at $\mathrm{p}<0.05$. Briefly, substantial heterogeneity was defined as $\mathrm{I}^{2}$ of greater than $50 \%$. Funnel plots were visually inspected to determine publication bias.

Sensitivity analyses were conducted within RevMan to explore any evidence of small-study effects within the included trials and any trials that were removed due to risk of bias. Sensitivity analyses were conducted using the leave-one-out method, which simultaneously applies the random effect models while omitting a single trial at a time to explore any effect this may have had on outcome MDs.

\section{Subgroup analyses}

Subgroup analyses using training status (untrained vs trained) and age (young: $<45$ years; old: $>45$ years) were performed as categorical variables using RevMan. Training status was retrieved using the included trial's definition for trained versus untrained, and where a trial failed to report training status the group was categorised as untrained. Subgroup analyses for both conditions were conducted on the mean change in TBM, FFM and 1RM lower body and 1RM upper body outcome measures.

\section{RESULTS}

\section{Included studies}

The combined search yield was 3695 scientific studies. A secondary search involved consulting experts in the field and revising reference lists of other reviews and meta-analyses on the subject (five studies). After removing duplicate records and screening for inclusion criteria, 69 articles were independently reviewed by two authors (KRO and TMD). A total of 35 randomised controlled trials (RCTs) were selected for inclusion in this meta-analysis (figure 1). 


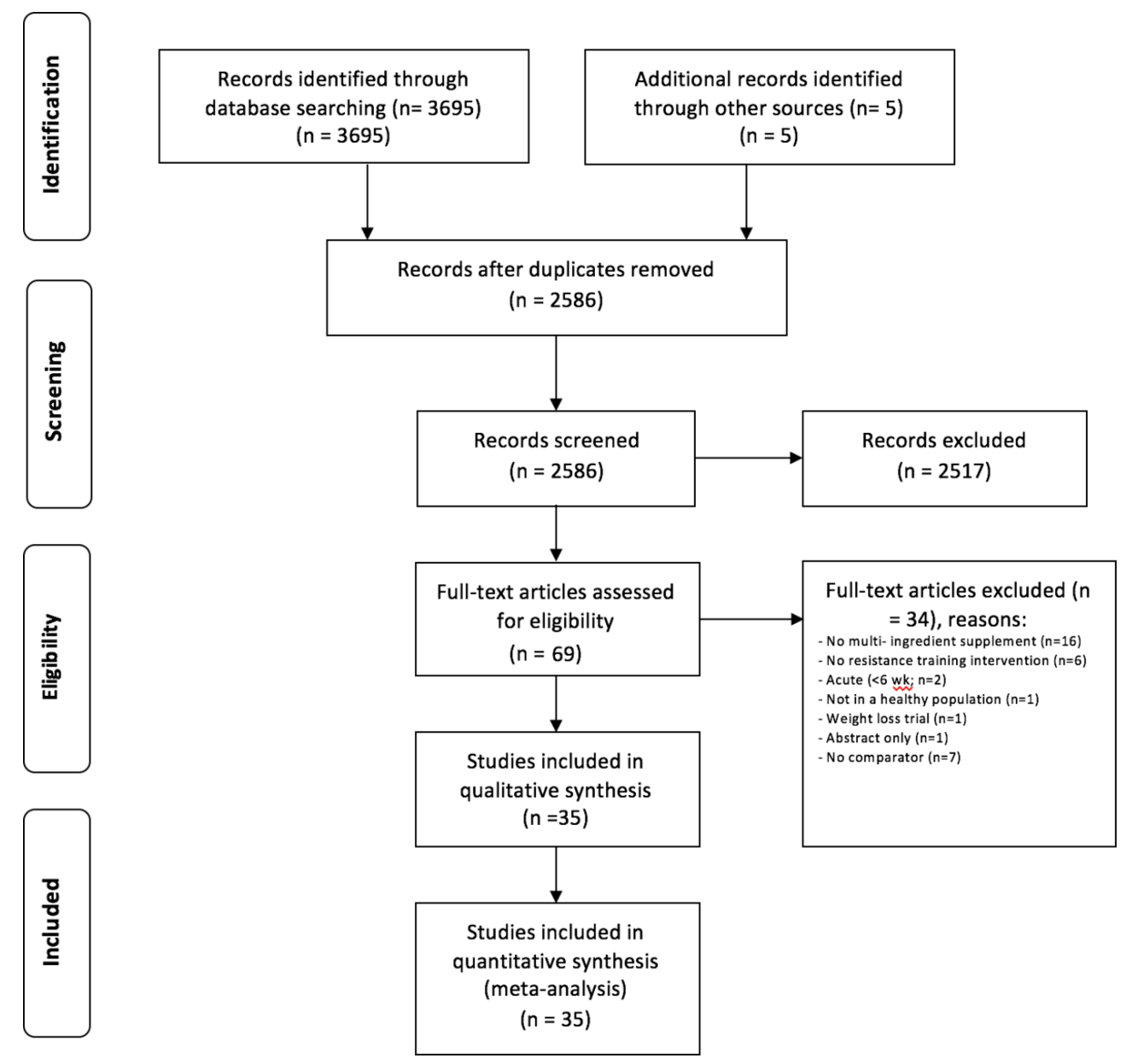

Figure 1 PRISMA flow chart of studies evaluated in the systematic review. PRISMA, Preferred Reporting Items for Systematic Reviews and MetaAnalyses.

\section{Participant characteristics}

The participant and outcome details of all trials are listed in table 1 . A total of 35 trials met the inclusion criteria with publication dates ranging from 2001 to 2017 . The pooled number of participants across included trials was 1387 (mean \pm SD; age: $46 \pm 21$ years), including 361 female participants. Sample sizes in individual trials ranged from 6 to 69 with 11 trials including participants with previous RT experience.

\section{RT protocol characteristics}

The RT programme characteristics and trial outcomes are summarised in table 1 . The duration of RT programmes ranged from 6 weeks to 78 weeks ( $16 \pm 14$ weeks) with a training frequency between 2 days and 5 days per week ( $3 \pm 1$ days/ week), 1-12 exercises per session (7 \pm 3 exercises/session), 1-6 sets per exercise $(3 \pm 1$ sets/exercise) and $4-15$ repetitions per set $(9 \pm 2$ repetitions/set). Thirty-one trials reported supervised RT interventions, with most reporting a progressive overload approach to RT.

\section{MIP supplementation characteristics}

Summarised details of the MIP supplementation and control (PRO, PLA and RT) groups are reported in online supplementary table 1 . A range of $10-101 \mathrm{~g}$ of additional protein was supplemented each day to MIP experimental groups (36 $\pm 21 \mathrm{~g} /$ day), with five studies prescribing daily doses relative to body weight (g/kg/day) of between 0.3 and $1.2 \mathrm{~g} / \mathrm{kg} /$ day. Thirty-two studies used whey protein, three whey/casein, two milk or milk protein and one with whole food (yoghurt) and nine with unspecified proprietary blends. Seventeen MIP conditions provided a protein-based supplement that included $\mathrm{Cr}, 10$ with $\mathrm{CHO}$ plus $\mathrm{Cr}, 6$ with $\mathrm{CHO}$ only and 2 with colostrum. The doses of $\mathrm{Cr}$ used in MIP supplemented groups were between $3 \mathrm{~g}$ and $5.1 \mathrm{~g}$ and between $0.07 \mathrm{~g} / \mathrm{kg} / \mathrm{day}$ and $0.1 \mathrm{~g} / \mathrm{kg} /$ day. Ten studies used MIP blends with vit $\mathrm{D}$, five with Leu, six with L-glutamine, two with $\mathrm{HMB}$, two with PUFAs, one with beta-alanine and one with caffeine. In 15 studies, participants consumed MIP supplements as multiple doses per day, with 22 experimental groups consuming part, or all, their requirements immediately after RT training sessions. Twenty-five of the included studies reported either absolute $(\mathrm{g} /$ day) or relative $(\mathrm{g} / \mathrm{kg} /$ day) daily protein intake during the preintervention and/or postintervention time points.

\section{Risk of bias assessment}

Nine studies were excluded from the meta-analyses due to recording more than three high or unclear risk of bias domains ${ }^{23} 2627363840-4244$ (see online supplementary figure 1). The predominant domains contributing to risk of bias were inadequate reporting of sequence generation (22 of 35) and blinding of participants and personnel (9 of 35).

\section{Sensitivity analyses}

Sensitivity analysis was conducted with the nine excluded highrisk of bias studies. The inclusion of those excluded studies did 


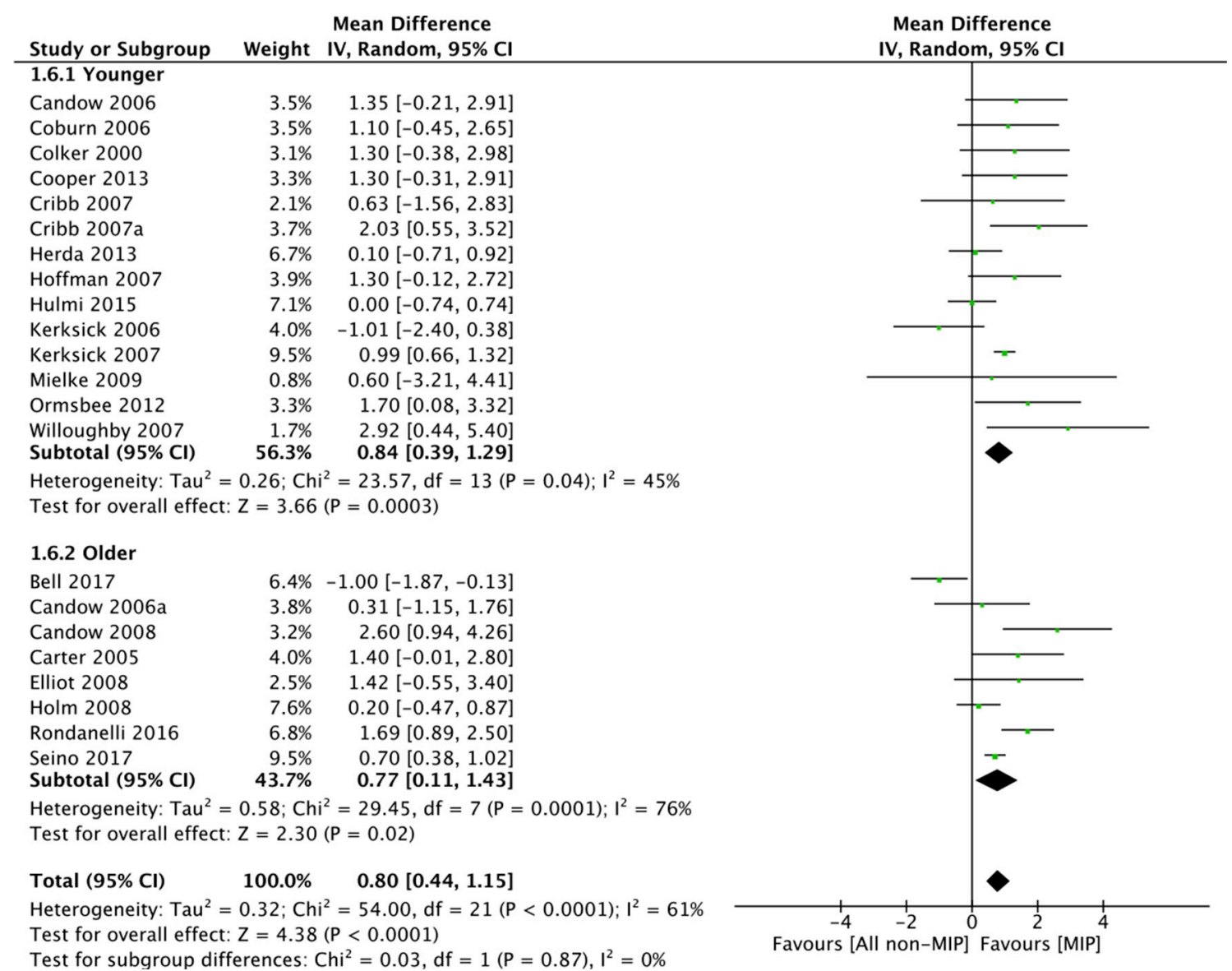

Figure 2 Forest plot of the results from a random effects meta-analysis for multi-ingredient protein (MIP) supplementation compared with all non-MIP supplementation groups shown as mean difference with $95 \% \mathrm{Cls}$ on lean or fat-free mass $(\mathrm{kg})$ in young $(<45$ years) and old ( $>45$ years) participants. For each trial, the square represents the mean difference of the intervention effect with the horizontal line intersecting it as the lower and upper limits of the $95 \% \mathrm{Cl}$. The size of the square represents the relative weight that trial carried in the meta-analysis. The rhombi represent the weight of young, old and total group's mean difference. Total: $0.80 \mathrm{~kg}(95 \% \mathrm{Cl} 0.44$ to 1.15$), \mathrm{p}<0.0001$; young: $0.84 \mathrm{~kg}(95 \% \mathrm{Cl} 0.34$ to 1.29$)$, $\mathrm{p}=0.0003$; old: 0.77 (95\% Cl 0.11 to 1.43$), \mathrm{p}=0.02$.

not substantially influence the difference in means or significance in any strength or body composition outcome. The use of random effects meta-analysis compared with fixed effect also did not affect the magnitude or significance of any of the results.

\section{Meta-analyses}

The meta-analysis results comparing MIP with all non-MIP conditions revealed significant increases in TBM (MD: $1.23 \mathrm{~kg}$ (95\% CI 0.76 to 1.70 ), $\mathrm{p}<0.0001$; online supplementary table 2) and FFM (MD: $0.80 \mathrm{~kg}(95 \%$ CI 0.44 to 1.15$), \mathrm{p}<0.0001$; figure 2) with no differences in FM (MD: $0.04 \mathrm{~kg}$ (95\% CI -0.47 to 0.54$), p=0.89$; online supplementary table 2 ). MIP supplementation during prolonged RT had a significant effect on 1RM upper body (MD: $2.56 \mathrm{~kg}$ (95\% CI 0.79 to 4.33 ), $\mathrm{p}=0.005$; figure 3$)$ and $1 \mathrm{RM}$ lower body (MD: $4.22 \mathrm{~kg}(95 \% \mathrm{CI}$ 0.79 to 7.64$), p=0.02$; figure 4 ) for the MIP versus all non-MIP group comparison.

Comparison of MIP and PRO only data (see online supplementary table 3) showed MIP supplementation increased FM (MD: $0.76 \mathrm{~kg}$ (95\% CI 0.13 to 1.40$), \mathrm{p}=0.02$ ) with no differences in TBM (MD: $0.65 \mathrm{~kg}(95 \% \mathrm{CI}-0.45$ to 1.78$), \mathrm{p}=0.24)$, FFM (MD: $0.39 \mathrm{~kg}(95 \% \mathrm{CI}-0.28$ to 1.05$), \mathrm{p}=0.26), 1 \mathrm{RM}$ lower body (MD: $1.33 \mathrm{~kg}$ (95\% CI -3.81 to 6.48$), \mathrm{p}=0.61$ ) and $1 \mathrm{RM}$ upper body (MD: $0.01 \mathrm{~kg}$ (95\% CI -4.16 to 4.18 ), $\mathrm{p}=1.00)$.
The statistical test results for assessing heterogeneity are presented in online supplementary tables 2 and 3. Significant heterogeneity was identified in the MIP versus all non-MIP comparison outcome changes in FFM $\left(\mathrm{X}^{2}=53.82, \mathrm{I}^{2}=61 \%\right.$, $\mathrm{p}=0.0001)$. Similarly, in the MIP versus PRO group comparison, significant heterogeneity was calculated for changes in FFM $\left(X^{2}=19.61, I^{2}=64 \%, p=0.006\right.$, online supplementary table 3$)$. Funnel plots were used to assess publication bias in FFM, 1RM upper body and 1RM lower body outcome measures (see online supplementary figure 2). Symmetrical funnel plots indicate that publication bias is unlikely with a wide scatter of smaller studies at the bottom of the graph and the spread narrowing among larger studies.

\section{Subgroup analysis}

Subgroup analyses are presented in online supplementary table 2 . In young participants ( $<45$ years; $24 \pm 4$ years), gains in TBM (MD: $\mathrm{kg} 1.12$ [95\% CI 0.37 to 1.87 ], p=0.02), FFM (MD: $0.84 \mathrm{~kg}(95 \%$ CI 0.34 to 1.29$), \mathrm{p}=0.0003$; figure 5 ) and $1 \mathrm{RM}$ lower body (MD: $4.83 \mathrm{~kg}$ (95\% CI 1.05 to 8.62 ), $\mathrm{p}=0.01$ ) were augmented with MIP compared with non-MIP supplements, while no difference was found in 1RM upper body (MD: $3.03 \mathrm{~kg}$ (95\% CI -0.07 to 6.14$), \mathrm{p}=0.06$ ). In older adults ( $>45$ years; $66 \pm 8$ years), gains in TBM (MD: $1.10 \mathrm{~kg}$ (95\% CI 0.24 to 1.96 ), $\mathrm{p}=0.01)$, FFM (MD: $0.77 \mathrm{~kg}(95 \%$ CI 0.11 to 1.43$), \mathrm{p}=0.02)$ 


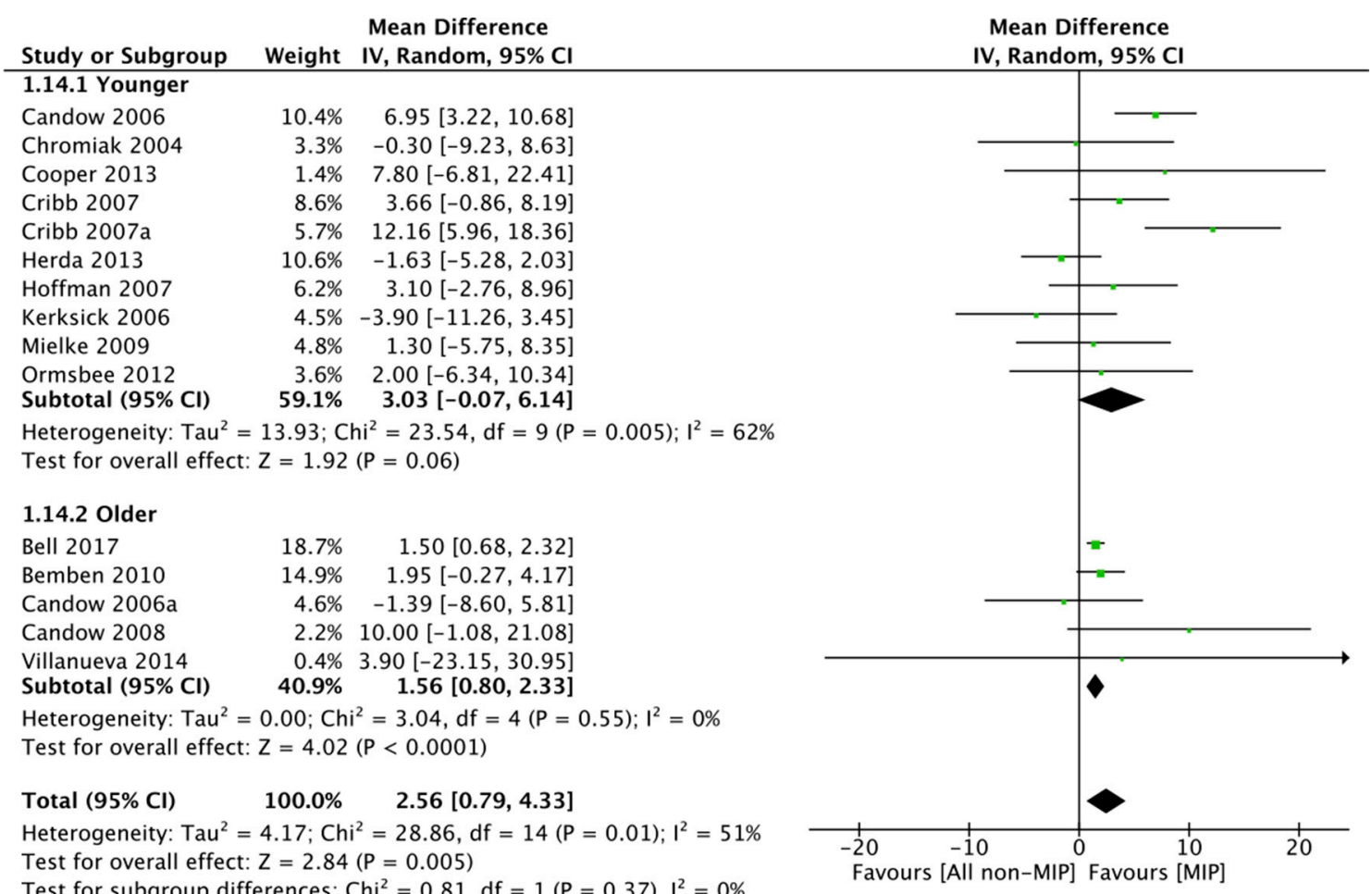

Figure 3 Forest plot of the results from a random effects meta-analysis for multi-ingredient protein (MIP) supplementation compared with all non-MIP supplementation groups shown as mean difference with $95 \% \mathrm{Cls}$ on one-Repetition maximum upper body $(\mathrm{kg})$ in young $(<45$ years) and old ( $>45$ years) participants. For each trial, the square represents the mean difference of the intervention effect with the horizontal line intersecting it as the lower and upper limits of the $95 \% \mathrm{Cl}$. The size of the square represents the relative weight that trial carried in the meta-analysis. The rhombi represent the weight of young, old and total group's mean difference. Total: $2.56 \mathrm{~kg}(95 \% \mathrm{Cl} 0.79$ to 4.33$), \mathrm{p}=0.005$; young: $3.03 \mathrm{~kg}(95 \% \mathrm{Cl}-0.07$ to 6.14), $p=0.06$; old: 1.56 (95\% Cl 0.80 to 2.33), $p<0.0001$.

and 1RM upper body (MD: $1.56 \mathrm{~kg}$ (95\% CI 0.80 to 2.33 ), $\mathrm{p}<0.0001)$ were augmented with MIP compared with non-MIP supplements; however, there was no effect on 1RM lower body (MD: $3.36 \mathrm{~kg}$ (95\% CI -4.06 to 10.78), $\mathrm{p}=0.38$ ).

Trained participants had increased gains in TBM (MD: $1.24 \mathrm{~kg}$ (95\% CI 0.18 to 2.29$), \mathrm{p}=0.02$ ) and $1 \mathrm{RM}$ upper body (MD: $3.28 \mathrm{~kg}(95 \%$ CI 0.14 to 6.42; figure 3), $\mathrm{p}=0.04$ ) with MIP compared with non-MIP supplementation, with no effect on FFM (MD: $0.62 \mathrm{~kg}(95 \% \mathrm{CI}-0.04$ to 1.28 ; figure 4$), \mathrm{p}=0.06)$ or 1RM lower body (MD: $4.23 \mathrm{~kg}$ (95\% CI -2.32 to 10.78 ; figure 1$), p=0.21)$. In untrained participants, there was no difference in 1RM lower body (MD: $4.23 \mathrm{~kg}(95 \% \mathrm{CI}-0.01$ to 8.46), $\mathrm{p}=0.05$ ) and 1RM upper body (MD: 2.09 (95\% CI -0.65 to 4.83$), \mathrm{p}=0.13$ ) with MIP compared with non-MIP supplements; however, gains in TBM (MD: $1.16 \mathrm{~kg}$ (95\% CI 0.72 to 1.60$), \mathrm{p}<0.0001)$ and FFM (MD: $0.95 \mathrm{~kg}(95 \%$ CI 0.51 to 1.39 ), $\mathrm{p}<0.0001$ ) were augmented with MIP in the untrained.

Despite only four studies satisfying the criteria and a single variable able to be analysed, MIP supplements containing CR were compared with PRO supplements; FFM was increased with MIP containing CR by a mean $1.01 \mathrm{~kg}$ (95\% CI 0.69 to 1.33 ; $\mathrm{p}<0.00001)$.

\section{Effects of interventions}

The quality of evidence for one outcome (TBM) was considered to be of high quality, while the remaining variables (FFM, FM, 1RM lower body and 1RM upper body) were considered to be of moderate quality. None of the outcomes were rated as being low quality evidence. The GRADE quality assessment results can be found in online supplementary table 4 .

\section{DISCUSSION}

This review is the most comprehensive meta-analysis to date to determine the effect of MIP supplementation on RT-induced gains in muscle mass and strength in adults. We provide novel data showing MIP supplements enhance RT-induced gains in TBM, FFM and upper and lower body strength when compared with all non-MIP interventions. The meta-analysis also shows that while the increase in TBM and FFM with MIP supplementation was evident in both young and old participant subgroups, increased upper body strength was only observed in older individuals with MIP versus all non-MIP interventions. Conversely, MIP supplementation resulted in significant increases in lower body strength only within younger participants. Of note, no significant changes in TBM and FFM were observed when MIP and PRO supplements were compared.

The pooled estimates from the present study show MIP supplementation during prolonged RT ( $\geq 6$ weeks) augments gains in FFM and upper and lower body strength, when compared with all other non-MIP supplemented conditions. MIP formulations employed by the RT studies for this review included any protein source combined with other putative anabolic compounds such as Cr, Leu and HMB and/or additional macronutrients/micronutrients including $\mathrm{CHO}$, vit $\mathrm{D}$ and PUFAs. Of note, five of the control conditions included a PRO supplemented group, 2235474852 which likely reduced the calculated effect size when pooled into the non-MIP conditions. Our data for FFM and upper body 1RM are mostly in agreement with Naclerio and Larumbe-Zabala, ${ }^{15}$ who report improvements in FFM and 1RM upper body, but not 1RM lower body, in 118 young 'strength trained' male participants consuming 


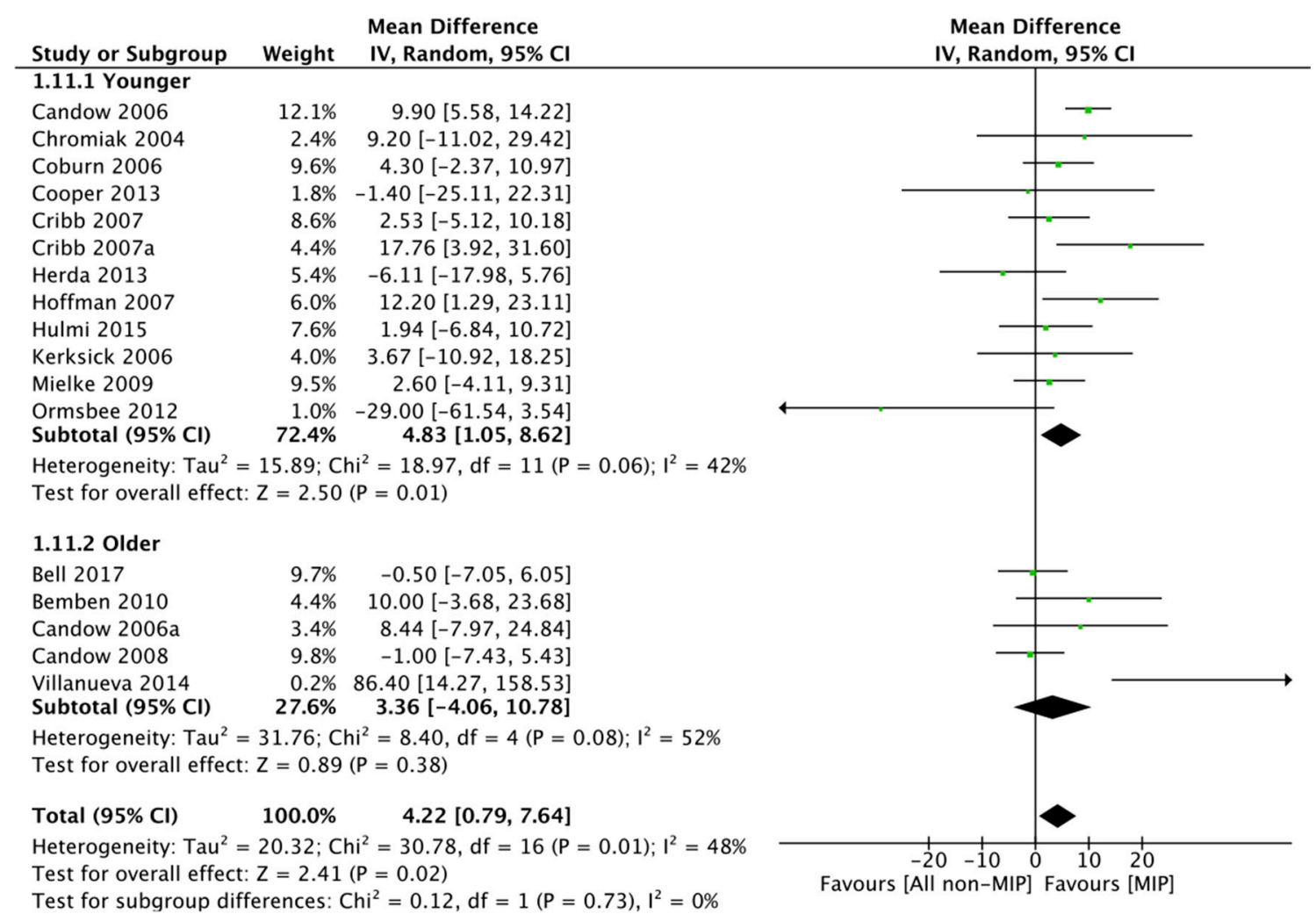

Figure 4 Forest plot of the results from a random effects meta-analysis for multi-ingredient protein (MIP) supplementation compared with all nonMIP supplementation groups shown as mean difference with $95 \% \mathrm{Cls}$ on one-repetition maximum lower body (kg) in young (<45 years) and old ( $>45$ years) participants. For each trial, the square represents the mean difference of the intervention effect with the horizontal line intersecting it as the lower and upper limits of the $95 \% \mathrm{Cl}$. The size of the square represents the relative weight that trial carried in the meta-analysis. The rhombi represent the weight of young, old and total group's mean difference. Total: $4.22 \mathrm{~kg}(95 \% \mathrm{Cl} 0.79$ to 7.64$), \mathrm{p}=0.02$, young: $4.83 \mathrm{~kg}(95 \% \mathrm{Cl} 1.05 \mathrm{to} 8.62)$, $\mathrm{p}=0.01$; old: $3.36(95 \% \mathrm{Cl}-4.06$ to 10.78$), \mathrm{p}=0.38$.

only whey protein containing MIP supplements. In contrast, our data also show an increase in 1RM lower body, although subgroup analysis for age suggests this effect is more consistently observed in younger participants. The additional trials in our analysis compared with that of Naclerio and Larumbe-Zabala ${ }^{15}$ may explain the discrepancies in findings, specifically the improvement of 1RM lower body with MIP supplementation. Regardless, our meta-analysis of 1387 participants extends these findings to provide new data showing MIP supplementation is associated with additional increases in TBM and lower body strength across divergent populations undertaking RT. Consequently, the use of MIP supplements has potential to promote the benefits associated with RT including increased skeletal muscle mass and strength.

The MIP formulations included in 14 studies contained Cr, which has been shown to enhance upper ${ }^{53}$ and lower body strength in several populations. ${ }^{54} 55 \mathrm{~A}$ recent meta-analysis ${ }^{8}$ in $>700$ older adults found that $\mathrm{Cr}$ supplementation during RT

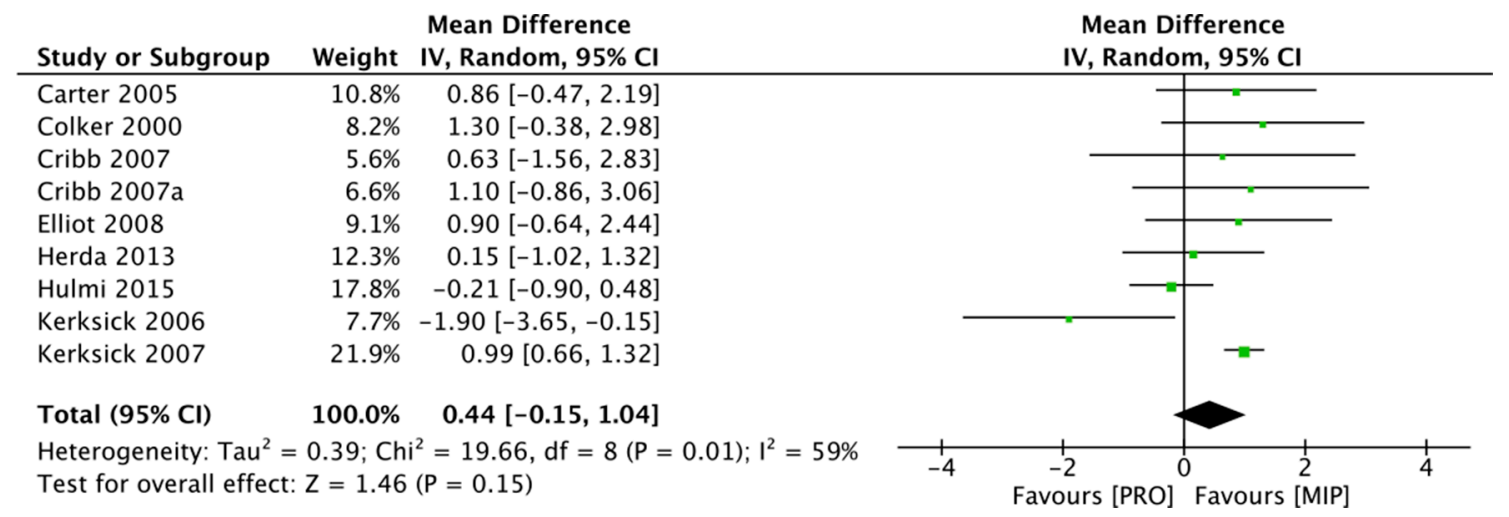

Figure 5 Forest plot of the results from a random effects meta-analysis for multi-ingredient protein (MIP) supplementation compared with protein-only supplementation groups shown as mean difference with $95 \% \mathrm{Cls}$ on lean or fat-free mass (kg). For each trial, the square represents the mean difference of the intervention effect with the horizontal line intersecting it as the lower and upper limits of the $95 \% \mathrm{Cl}$. The size of the square represents the relative weight that trial carried in the meta-analysis. The rhombus represents the group's mean difference. Total: $0.44 \mathrm{~kg}(95 \% \mathrm{Cl}$ -0.15 to 1.04$), p=0.15$. 
( $>5$ weeks, 2-3 days/week) significantly increased lean tissue mass by $\sim 1.4 \mathrm{~kg}$ when compared with PLA. Cr supplementation is purported to elevate high energy phosphate resynthesis in skeletal muscle to promote greater work capacity during short duration exercise and has potential to increase intramuscular water content. ${ }^{56}$ Accordingly, the mechanisms of action of $\mathrm{Cr}$ are complimentary to RT and likely contributed increases in mass and strength observed with MIP supplementation in this meta-analysis. The potential for other multi-ingredient components to provide an additive effect to RT is less clear, but free Leu has been shown to augment acute muscle protein synthesis in response to RT, ${ }^{57}$ although this beneficial effect may be limited to protocols that provide a suboptimal protein dose during the early postexercise recovery period. Emerging evidence may also support the efficacy of supplementation with PUFAs $(\sim 3 \mathrm{~g}$ per day) to maintain muscle mass and function in older adults. ${ }^{1058}$ However, further work is required to clearly define the contributions of various multi-ingredients to protein-based supplementation for promoting skeletal muscle gains and function with RT across the lifespan.

Subgroup analysis showed that MIP supplementation was effective in older persons. Compared with younger participants, the MIP supplemented older cohorts ( $>45$ years) showed greater improvements in upper body strength, with comparable gains in TBM and FFM. The underlying pathology of progressive muscle loss in older individuals is multifactorial and an anabolic resistance has been reported in older populations. ${ }^{59}$ Our results show that older individuals (16 trials) undertaking prolonged RT in conjunction with MIP supplementation are capable of significant gains in FFM that were analogous to that achieved by younger persons. MIP supplementation may provide additional nutrition to promote skeletal muscle anabolic responses to RT but also increases total energy intake that may assist in meeting total energy requirements in older individuals. Indeed, the use of MIP supplements in addition to RT appears a logical strategy to counteract the progression of the age-associated decline in muscle mass, strength and physical function to mitigate negative health implications, including metabolic disease, decreased independence, frailty and mortality. ${ }^{6061}$ Further subgroup analysis for RT status showed a greater effect of MIP on FFM gains in untrained compared with trained participants (12 trials). However, these results should be interpreted with some caution, as there was a high level of heterogeneity in participants' training status within the included trials; some trials failed to report training status (six trials), while others classified 'trained' status as anywhere from $>6$ months' up to $>2$ years' RT experience. Nonetheless, our findings support the notion that untrained participants may have an increased postexercise protein turnover and a greater potential for gains in FFM, predominantly skeletal muscle, compared with those with prolonged training history and reduced muscle plasticity. ${ }^{162} 63$

Additional benefits of MIP over PRO supplementation (see online supplementary table 3 ) under the same RT conditions is an essential consideration for identifying the most appropriate strategies to optimise RT-induced gains in mass and strength across the population. Our findings do not support an additive effect of MIP compared with PRO supplements on TBM and FFM or strength responses to RT. It seems reasonable to suggest that variation in the constituents of the MIP supplements may have reduced the potential to detect meaningful effects compared with protein in isolation. Indeed, MD consistently favoured MIP versus PRO for each variable of interest in the present review. Regardless, a practical consideration from our data is that any use of an MIP supplement to promote RT-induced gains in skeletal muscle mass should include substantial protein content. Moreover, our findings indicate that MIP supplementation resulted in greater increases in FM compared with PRO supplementation, which may have an important practical application for persons who have poor nutritional status or elevated energy requirements.

\section{Quality of evidence}

Based on the quality of evidence assessment of the analysed outcome measures, we can conclude that the results obtained in this review were not influenced by low-quality methodological study designs. We found the quality of evidence for most outcomes to be of moderate quality, primarily due to inconsistency through statistical heterogeneity as a result of the methodological differences between trials that were not explained by the subgroup factors.

\section{Limitations}

First, our meta-analyses included only retrievable RCTs that were published in English, which may have possible implications for language bias and should be recognised as a limitation. Moderate statistical heterogeneity was also detected in this meta-analysis indicating a high degree of trial variability. Accordingly, all meta-analyses data were presented using a 'random-effects model' to assume the effects follow a specific distribution even though we acknowledge that this method does not completely remove heterogeneity. ${ }^{50}$ We identified several sources of heterogeneity across the included trials: participant characteristics, supplement composition, supplementation timing, protein dose (range of $10 \mathrm{~g}-101 \mathrm{~g}$ per day), RT duration (range of 6-78 weeks), RT variables (range of 1-12 exercises and 1-6 sets per exercise) and strength testing measures (range of 2-7 different RM tests). Although the mean protein dose was $36 \pm 21 \mathrm{~g} /$ day, we suspect that the large range (10-101 g per day) would have generated substantial variation and may explain why some participants appear non-responsive to supplementation.

\section{CONCLUSION}

Dietary MIP supplements augment the increase in FFM and strength with resistance training of 6-78 weeks. MIP supplementation improves the exercise-induced gains in TBM and FFM irrespective of chronological age and may enhance strength in older individuals. MIP supplementation is not superior to PRO supplements in augmenting RT adaptation. MIP supplements combined with RT augment peak muscle mass in early adulthood and may reduce the loss of muscle quality and quantity with ageing.

Acknowledgements The authors wish to extend our sincere gratitude to David Honeyman for assisting with the refinement and execution of the search strategy and Dr Jaimon Kelly for directing the processes and development of this systematic review.

Contributors All authors contributed to the conception and design of the study. KRO and RWM contributed to the development and implementation of the search strategy. KRO and TMD completed the acquisition of data. KRO and TMD conducted the data analysis. All authors contributed with the interpretation. KRO and TMD were the principal authors of the manuscript. All authors contributed to the drafting and revision of the final manuscript. All authors approved the final version of the article.

Funding The authors have not declared a specific grant for this research from any funding agency in the public, commercial or not-for-profit sectors.

Competing interests SMP has received grant support, travel expenses and honoraria for presentations from the US National Dairy Council. This agency has supported trials reviewed in this analysis.

Provenance and peer review Not commissioned; externally peer reviewed. 


\section{REFERENCES}

1 Damas F, Phillips S, Vechin FC, et al. A review of resistance training-induced changes in skeletal muscle protein synthesis and their contribution to hypertrophy. Sports Med 2015;45:801-7.

2 Cermak NM, Res PT, de Groot LC, et al. Protein supplementation augments the adaptive response of skeletal muscle to resistance-type exercise training: a metaanalysis. Am J Clin Nutr 2012;96:1454-64.

3 Morton RW, Murphy KT, McKellar SR, et al. A systematic review, meta-analysis and meta-regression of the effect of protein supplementation on resistance traininginduced gains in muscle mass and strength in healthy adults. Br J Sports Med 2018:52:bjsports-2017-097608.

4 Liao CD, Tsauo JY, Wu YT, et al. Effects of protein supplementation combined with resistance exercise on body composition and physical function in older adults: a systematic review and meta-analysis. Am J Clin Nutr 2017;106:1078-91.

5 Reidy PT, Rasmussen BB. Role of ingested amino acids and protein in the promotion of resistance exercise-induced muscle protein anabolism. J Nutr 2016;146:155-83.

6 Thomas DK, Quinn MA, Saunders DH, et al. Protein supplementation does not significantly augment the effects of resistance exercise training in older adults: a systematic review. J Am Med Dir Assoc 2016;17:959.e1-9.

7 Bell KE, Snijders T, Zulyniak M, et al. A whey protein-based multi-ingredient nutritional supplement stimulates gains in lean body mass and strength in healthy older men: A randomized controlled trial. PLoS One 2017;12:e0181387.

8 Chilibeck PD, Kaviani M, Candow DG, et al. Effect of creatine supplementation during resistance training on lean tissue mass and muscular strength in older adults: a metaanalysis. Open Access J Sports Med 2017;8:213-26.

9 Tomlinson PB, Joseph C, Angioi M. Effects of vitamin D supplementation on upper and lower body muscle strength levels in healthy individuals. A systematic review with meta-analysis. J Sci Med Sport 2015;18:575-80.

10 Smith GI, Julliand S, Reeds DN, et al. Fish oil-derived n-3 PUFA therapy increases muscle mass and function in healthy older adults. Am J Clin Nutr 2015;102:115-22.

11 Devries MC, Phillips SM. Creatine supplementation during resistance training in older adults-a meta-analysis. Med Sci Sports Exerc 2014;46:1194-203.

12 Chiang CM, Ismaeel A, Griffis RB, et al. Effects of Vitamin D Supplementation on muscle strength in athletes: a systematic review. J Strength Cond Res 2017;31:566-74.

13 Smith GI, Atherton P, Reeds DN, et al. Dietary omega-3 fatty acid supplementation increases the rate of muscle protein synthesis in older adults: a randomized controlled trial. Am J Clin Nutr 2011;93:402-12.

14 Yoshino J, Smith GI, Kelly SC, et al. Effect of dietary n-3 PUFA supplementation on the muscle transcriptome in older adults. Physiol Rep 2016;4:e12785.

15 Naclerio F, Larumbe-Zabala E. Effects of whey protein alone or as part of a multiingredient formulation on strength, fat-free mass, or lean body mass in resistancetrained individuals: a meta-analysis. Sports Med 2016;46:125-37.

16 Beck TW, Housh TJ, Johnson GO, et al. Effects of a drink containing creatine, amino acids, and protein combined with ten weeks of resistance training on body composition, strength, and anaerobic performance. J Strength Cond Res 2007;21:100-4

17 Candow DG, Burke NC, Smith-Palmer T, et al. Effect of whey and soy protein supplementation combined with resistance training in young adults. Int I Sport Nutr Exerc Metab 2006;16:233-44.

18 Candow DG, Chilibeck PD, Facci M, et al. Protein supplementation before and after resistance training in older men. Eur J App/ Physiol 2006:97:548-56.

19 Candow DG, Little JP, Chilibeck PD, et al. Low-dose creatine combined with protein during resistance training in older men. Med Sci Sports Exerc 2008:40:1645-52.

20 Holm L, Olesen JL, Matsumoto K, et al. Protein-containing nutrient supplementation following strength training enhances the effect on muscle mass, strength, and bone formation in postmenopausal women. J App/ Physiol 2008; 105:274-81.

21 Kerksick CM, Rasmussen C, Lancaster S, et al. Impact of differing protein sources and a creatine containing nutritional formula after 12 weeks of resistance training. Nutrition 2007;23:647-56

22 Kerksick CM, Rasmussen CJ, Lancaster SL, et al. The effects of protein and amino acid supplementation on performance and training adaptations during ten weeks of resistance training. J Strength Cond Res 2006;20:643-53.

23 Kukuljan S, Nowson CA, Sanders K, et al. Effects of resistance exercise and fortified milk on skeletal muscle mass, muscle size, and functional performance in middle-aged and older men: an 18-mo randomized controlled trial. J App/ Physiol 2009; 107:1864-73.

24 Villanueva MG, He J, Schroeder ET. Periodized resistance training with and without supplementation improve body composition and performance in older men. Eur J App/ Physiol 2014;114:891-905.

25 Ormsbee MJ, Mandler WK, Thomas DD, et al. The effects of six weeks of supplementation with multi-ingredient performance supplements and resistance training on anabolic hormones, body composition, strength, and power in resistancetrained men. J Int Soc Sports Nutr 2012;9:49.

26 Willems ME, Sallis CW, Haskell JA. Effects of multi-ingredient supplementation on resistance training in young males. J Hum Kinet 2012;33:91-101.
27 Bunout B, Barrera G, de la Maza P, et al. Effects of nutritional supplementation and resistance training on muscle strength in free living elders. Results of one year follow. J Nutr Health Aging 2004;8:68-75.

28 Bemben MG, Witten MS, Carter JM, et al. The effects of supplementation with creatine and protein on muscle strength following a traditional resistance training program in middle-aged and older men. J Nutr Health Aging 2010;14:155-9.

29 Chromiak JA, Smedley B, Carpenter W, et al. Effect of a 10-week strength training program and recovery drink on body composition, muscular strength and endurance, and anaerobic power and capacity. Nutrition 2004;20:420-7.

30 Coburn JW, Housh DJ, Housh TJ, et al. Effects of leucine and whey protein supplementation during eight weeks of unilateral resistance training. J Strength Cond Res 2006;20:284-91.

31 Colker CM, Swain MA, Fabrucini B, et al. Effects of supplemental protein on body composition and muscular strength in healthy athletic male adults. Current Therapeutic Research 2000:61:19-28.

32 Cooper R, Naclerio F, Larumbe-Zabala E, et al. Effects of a carbohydrate-proteincreatine supplement on strength performance and body composition in recreationally resistance trained young men. Journal of Exercise Physiology Online 2013;16:72-85.

33 Herda AA, Herda TJ, Costa PB, et al. Muscle performance, size, and safety responses after eight weeks of resistance training and protein supplementation: a randomized, double-blinded, placebo-controlled clinical trial. J Strength Cond Res 2013;27:3091-100.

34 Hoffman JR, Ratamess NA, Kang J, et al. Effects of protein supplementation on muscular performance and resting hormonal changes in college football players. $J$ Sports Sci Med 2007;6:85-92.

35 Hulmi JJ, Laakso M, Mero AA, et al. The effects of whey protein with or without carbohydrates on resistance training adaptations. J Int Soc Sports Nutr 2015;12:48.

36 Maltais ML, Ladouceur JP, Dionne IJ. The effect of resistance training and different sources of postexercise protein supplementation on muscle mass and physical capacity in sarcopenic elderly men. J Strength Cond Res 2016;30:1680-7.

37 Mielke M, Housh TJ, Malek MH, et al. The effects of whey protein and leucine supplementation on strength, muscular endurance, and body composition during resistance training. Journal of Exercise Physiology Online 2009;12:39-50.

38 Oesen S, Halper B, Hofmann M, et al. Effects of elastic band resistance training and nutritional supplementation on physical performance of institutionalised elderly--a randomized controlled trial. Exp Gerontol 2015;72:99-108.

39 Seino S, Sumi K, Narita M, et al. Effects of low-dose dairy protein plus micronutrient supplementation during resistance exercise on muscle mass and physical performance in older adults: a randomized, controlled trial. J Nutr Health Aging 2018;22:1-9.

40 Stragier S, Baudry S, Poortmans J, et al. Leucine-enriched protein supplementation does not influence neuromuscular adaptations in response to a 6-month strength training programme in older adults. Exp Gerontol 2016;82:58-66.

41 Westcott W, Varghese J, DiNubile N, et al. Exercise and nutrition more effective than exercise alone for increasing lean weight and reducing resting blood pressure. Journal of Exercise Physiology Online 2011;14:120-33.

42 White KM, Bauer SJ, Hartz KK, et al. Changes in body composition with yogurt consumption during resistance training in Women. Int J Sport Nutr Exerc Metab 2009;19:18-33.

43 Willoughby DS, Stout JR, Wilborn CD. Effects of resistance training and protein plus amino acid supplementation on muscle anabolism, mass, and strength. Amino Acids 2007;32:467-77

44 Burke DG, Chilibeck PD, Davidson KS, et al. The effect of whey protein supplementation with and without creatine monohydrate combined with resistance training on lean tissue mass and muscle strength. Int J Sport Nutr Exerc Metab 2001:11:349-64.

45 Carter JM, Bemben DA, Knehans AW, et al. Does nutritional supplementation influence adaptability of muscle to resistance training in men aged 48 to 72 years. J Geriatr Phys Ther 2005;28:40-7.

46 Cribb PJ, Williams AD, Hayes A. A creatine-protein-carbohydrate supplement enhances responses to resistance training. Med Sci Sports Exerc 2007;39:1960-8.

47 Cribb PJ, Williams AD, Stathis CG, et al. Effects of whey isolate, creatine, and resistance training on muscle hypertrophy. Med Sci Sports Exerc 2007;39:298-307.

48 Eliot KA, Knehans AW, Bemben DA, et al. The effects of creatine and whey protein supplementation on body composition in men aged 48 to 72 years during resistance training. J Nutr Health Aging 2008;12:208-12.

49 Rondanelli M, Klersy C, Terracol G, et al. Whey protein, amino acids, and vitamin D supplementation with physical activity increases fat-free mass and strength, functionality, and quality of life and decreases inflammation in sarcopenic elderly. Am J Clin Nutr 2016;103:830-40.

50 Higgins.. Cochrane Handbook for Cochrane Handbook for Systematic Reviews of Interventions: The Cochrane Collaboration, 2011.

51 Ryan R, Hill S. How to GRADE the quality of the evidence Cochrane Consumers and Communication Group. 2016 http://ccrgcochraneorg/author-resources

52 Hickson M. Nutritional interventions in sarcopenia: a critical review. Proc Nutr Soc 2015;74:378-86

53 Lanhers C, Pereira B, Naughton G, et al. Creatine supplementation and upper limb strength performance: a systematic review and meta-analysis. Sports Med 2017;47:163-73 
54 Beaudart C, Dawson A, Shaw SC, et al. Nutrition and physical activity in the prevention and treatment of sarcopenia: systematic review. Osteoporos Int 2017;28:1817-33.

55 Lanhers C, Pereira B, Naughton G, et al. Creatine supplementation and lower limb strength performance: a systematic review and meta-analyses. Sports Med 2015:45:1285-94.

56 Hall M, Trojian TH. Creatine supplementation. Curr Sports Med Rep 2013;12:240-4.

57 Churchward-Venne TA, Breen L, Di Donato DM, et al. Leucine supplementation of a low-protein mixed macronutrient beverage enhances myofibrillar protein synthesis in young men: a double-blind, randomized trial. Am J Clin Nutr 2014;99:276-86.

58 Da Boit M, Sibson R, Sivasubramaniam S, et al. Sex differences in the effect of fish-oil supplementation on the adaptive response to resistance exercise training in older people: a randomized controlled trial. Am J Clin Nutr 2017;105:151-8.
59 Burd NA, Gorissen SH, van Loon LJ. Anabolic resistance of muscle protein synthesis with aging. Exerc Sport Sci Rev 2013;41:169-73.

60 Ali S, Garcia JM. Sarcopenia, cachexia and aging: diagnosis, mechanisms and therapeutic options - a mini-review. Gerontology 2014;60:294-305.

61 Phillips SM. Nutritional supplements in support of resistance exercise to counter agerelated sarcopenia. Adv Nutr 2015;6:452-60.

62 Brook MS, Wilkinson DJ, Mitchell WK, et al. Skeletal muscle hypertrophy adaptations predominate in the early stages of resistance exercise training, matching deuterium oxide-derived measures of muscle protein synthesis and mechanistic target of rapamycin complex 1 signaling. Faseb J 2015;29:4485-96.

63 Kim PL, Staron RS, Phillips SM. Fasted-state skeletal muscle protein synthesis after resistance exercise is altered with training. J Physiol 2005;568:283-90. 